out of Africa in the early Pleistocene.

Consideration of the evidence from the Middle East reveals equally interesting debates, including strong support for the earlier date of $90,000-100,000$ years before present for the origin of the modern forms at Qafzeh and a younger date $(50,000-60,000$ years before present) for the very robust Neanderthal skeleton at Kebara. A simple linear evolution from the Neanderthalers of Tabūn and Shanidar to the anatomically modern forms of Skhūl and Qafzeh now seems unlikely.

The authors of the African archaeological papers consider the transition from the middle to the later Palaeolithic and suggest that more complex behavioural patterns than previously thought can be inferred. In Europe, most of the occurrences of anatomically modern man seem to coincide with 'Aurignacian' industries, but other industrial variants are more mixed. The authors of several other papers consider the position in the Far East and Australasia as well as inferences concerning mental abilities, language and art, all of which raise fascinating questions fundamental to our appreciation of the evolution of modern man.

There is little doubt that this is an important book for all palaeoanthropologists and archaeologists - it is international in its scope and broad in its treatment of the exciting issues central to modern thinking in these fields. Although it is sad that it cannot take its place with the other volumes that emerged from the World Archaeological Congress, for which it was so painstakingly planned, it is a credit to its contributors and its editors as a most valuable contribution to the literature of human evolutionary studies.

Michael H. Day is an Emeritus Professor of Anatomy at London University and is in the Department of Palaeontology, British Museum (Natural History), London SW7 5BD, UK.

\section{Out of the bag}

\section{Stuart Sutherland}

Mind, Brain and the Quantum. By Michael Lockwood. Basil Blackwell: 1989. Pp. 365. £25, \$29.95.

RUMINATING on the relationships between the mind, the brain and quantum mechanics is not merely fashionable, it is becoming an industry. Philosophers apply quantum theory to the problems of consciousness, while physicists use consciousness to solve the paradoxes of quantum theory. Michael Lockwood does both.

Lockwood begins by dismissing the doctrine of functionalism, the idea that conscious states are to be thought of as brain states classified in terms of their causal relations with one another and with the external world. In doing so, he uses ingenious variants of the arguments from qualia, which basically depend on the fact that one could conceive of entities having states with the same functional relationships as those of mental states, but lacking conscious experience or having conscious experiences totally different from our own. He adopts a form of the identity theory - which is that consciousness is the same thing under another guise as certain brain states.

Mind, Brain and the Quantum is nothing if not bold. Its first daring stroke is an attempt to demonstrate that consciousness must be spatially located. Lockwood argues that because on the special theory of relatively "any two events which are temporally separated with respect to one frame of reference must be spatially separated with respect to some other frame" and because mental events are located in time, they must be located in space. Now consider a physical event A that causes a mental state $M$ which in turn causes another physical event $C$ : the mental event must lie within the future light cone of $\mathrm{A}$ and the past light cone of C. According to Lockwood, this places it in some part of the brain, but the argument contains a petitio principii, as it rests on the assumption that consciousness is in some sense a physical entity.

In resolving the problem of Schrödinger's cat, Lockwood starts from $\mathrm{H}$. Everett's theory that when a quantum system influences the macroscopic world, every possible outcome of the system occurs: the world branches into an infinity of different worlds. In contrast to Everett, Lockwood argues that macroscopic events can be in different and incompatible states simultaneously (Schrödinger's cat is both dead and alive) until they are observed, at which point each state enters one of a parallel stream of minds all belonging to the same observer. Although the observer is conscious of only one, he has an infinity of different lines of consciousness (biographies), each representing the sequence of macroscopic events produced by different outcomes of quantal events. In other words, Lockwood has changed Everett's notion that splitting into different worlds occurs whenever an unobserved quantum event influences the macroscopic world into the theory that the splitting takes place in consciousness (on observation). I am uncertain just what this gloss on Everett buys. According to Lockwood, the biography we happen to be in is related to the past by memory, but what happens when memories are false is not clear. Nor, come to that, is the status of Schrödinger's cat. Because we can always be mistaken, one can ask what it would mean to perceive the cat as dead, when it was really alive. It would be as embarrassing for Lockwood's theory as for the observer, if the wretched animal subsequently turned up demanding a bowl of milk.

Many of Lockwood's speculations about the brain are even more extraordinary. He suggests that there are phenomenological events of which we are not aware. If we are presented with monochromatic light of three wavelengths close together in the spectrum, we may be able to distinguish the lowest from the highest while not being able to tell the middle one from either of the other two. He concludes that the lowest and the highest must both be phenomenologically distinct from the middle one, even though we are not conscious of the distinction. But surely all one can conclude is that the members of the neighbouring pairs of wavelengths produce a difference in the activity of the nervous system that is too small to register in consciousness.

A further novel argument is that because conscious states are continuous whereas the firing of neurons is discrete, nerve impulses cannot underlie consciousness. This leads to the revolutionary suggestion that consciousness resides in the polarization of the dendrites, which Lockwood alleges is continuous. The argument can be refuted by a reductio ad absurdum. The polarization of neurons is itself no more discrete than their firing rates, for it depends on the number of individual ions lying on either side of the membrane.

Perhaps Lockwood's wildest fling is to suggest that the brain is a quantum computer. He struggles to overcome the problem that such a computer could only function in extreme cold, asserting that it might work if the temperature were kept constant - but the ratiocinatory abilities of alligators are far from negligible.

The book is densely but well written and deserves to be widely read. I have not been able to do justice to its curious mixture of careful and often highly ingenious philosophical arguments and its bizarre but interesting speculations. Lockwood, with characteristic wit, writes "there is nothing so obvious that a philosopher cannot be found to deny it". Philosophers may be hard put to find anything obvious in this book, but it is none the worse for that.

Stuart Sutherland is in the Centre for Research on Perception and Cognition, University of Sussex, Falmer, Brighton BN1 9QG, UK.

- Also recently published by Basil Blackwell, In and Out of the Black Box: On the Philosophy of Cognition by D. W. Hamlyn is an account of mental life and its effects on behaviour, meaning and consciousness. Price $£ 25, \$ 29.95$.

- From Reading to Neutrons, edited by A. M. Galaburda, is a formal approach to developmental disorders of cognition. Published by MIT Press, price $\$ 45, £ 40.50$. 